\title{
Assessment of sexually transmitted disease/HIV risk among young African Americans: comparison of self-perceived and epidemiological risks utilizing ecodevelopmental theory
}

This article was published in the following Dove Medical Press journal: HIVIAIDS - Research and Palliative Care

\author{
Ya-Huei Li' \\ Osaro Mgbere ${ }^{1-3}$ \\ Susan Abughosh' \\ Hua Chen' \\ Paula Cuccaro ${ }^{4}$ \\ Andrea Smesny' \\ Ekere James Essien 1,3,4 \\ 'Department of Pharmaceutical \\ Health Outcomes and Policy, \\ College of Pharmacy, University of \\ Houston, Houston, TX, USA; ' ${ }^{2}$ isease \\ Prevention and Control Division, \\ Houston Health Department, \\ Houston, TX, USA; ${ }^{3}$ Institute of \\ Community Health, University \\ of Houston, Houston, TX, USA \\ ${ }^{4}$ Department of Health Promotion \\ and Behavioral Sciences, University \\ of Texas School of Public Health, \\ Houston, TX, USA
}

Background: Recent advances in understanding the developmental processes associated with adolescents warrant new thinking and systematic application of key concepts of risk and protective processes. This study examined the association between epidemiological and self-perceived risks of contracting sexually transmitted diseases (STDs)/HIV among young African Americans (AAs) and the multilevel factors identified using ecodevelopmental theory.

Methods: A retrospective cross-sectional study was conducted on wave 1 data from the National Longitudinal Study of Adolescent Health comprising 1,619 AA youth aged 14-18 years. Epidemiological and self-perceived HIV-risk indices were developed and their associations with ecodevelopmental system parameters evaluated.

Results: Significant discordance $(P<0.0001)$ in the youths' self-perceived risk and epidemiological risk (the "gold standard") was recorded with Cohen's K-coefficient of 0.144 (95\% CI 0.104-0.193). Adolescents who felt like talking to their mother had no trouble getting along with schoolteachers, perceived that teachers treated student fairly, experienced mother's disapproval of their sexual debut, and had close friends who knew how to use condoms correctly, were positively related to low epidemiological risk of contracting STDs/HIV. Being older, male, and a mother's positive attitude toward their adolescent's use of birth control (in exosystem) were associated with high epidemiological risk of contracting STDs/HIV. Furthermore, poor connection with the mother (did not feel like talking to mother) and growing older were related to low accuracy of self-risk perception among AA youths. Conclusion: The findings demonstrate the strong need to align self-perceived risk with epidemiological risk of acquiring STDs/HIV using the key multilevel ecodevelopmental system factors identified. This will require changes in relevant social attitudes and norms associated with risk measurement, and allow for a rational basis for safe health practices and behaviors among AA youths. Keywords: self-perceived risk, epidemiological risk, STDs/HIV, ecodevelopmental theory, modeling, risk index, African American youths

\section{Introduction}

US national surveillance reports indicate that young Americans aged 13-24 years are most likely to be affected by HIV. ${ }^{1}$ The Centers for Disease Control and Prevention (CDC) noted that young people aged 13-24 years were the second-largest population diagnosed with HIV, and accounted for $21 \%$ of all HIV infections in $2013 .{ }^{1}$ Although people aged 24-34 years seem to be at the highest risk of contracting HIV, people aged 18-24 years had the highest rate of undiagnosed HIV. In 2012, about 44\% of 18- to 24-year-old Americans were living with HIV but not aware of it. ${ }^{1,2}$ The HIV epidemic
Correspondence: Ekere James Essien Institute of Community Health, University of Houston, Room 3044, Health Building 2, 4849 Calhoun Road, Houston, TX 77204, USA

Tel +l 8328428393

Email Ejessien@central.uh.edu 
in the nation has been fueled by delayed HIV diagnoses and low self-awareness of infection status, and this has led to poor health outcomes among young population., ${ }^{1,3}$

Among the most vulnerable population of youths, African Americans (AAs) were the most disproportionately affected by HIV when compared to other races/ethnicities. Despite the fact that young AAs represented only $14 \%$ of the young US population in 2013, ${ }^{1}$ they accounted for $67 \%$ and $57 \%$ of new HIV infections among the 13- to 19-year-old and 20- to 24-year-old population, respectively. ${ }^{1}$ Additionally, $76 \%$ of young people aged 13-19 years and $65 \%$ of young people aged 20-24 years were diagnosed with stage 3 HIV, also known as AIDS, in the same year. ${ }^{1}$ The high rate of new AIDS diagnoses among AA youths implied that a great proportion of young AAs were not aware of their HIVinfection status. ${ }^{1,3}$

Predicting sexually transmitted disease (STD)/HIV-infection risk is complex, because of the various factors that may be implicated with general apathy and lack of willingness to test for HIV. Studies ${ }^{1,4-7}$ have found that the association between homophobia and discrimination increases the risk of STD/ HIV contraction for those in the sexual minority. Others ${ }^{8-11}$ have indicated that the perceived low risk of contraction decreases youths' likelihood of condom use and HIV testing, effectively contributing to an increase in risk for contracting HIV. For example, the CDC established the Division of Adolescent and School Health ${ }^{2}$ to provide educational programs at schools, including behavioral intervention programs, such as the Becoming a Responsible Teen program. This program attempts to modify youths' sexual behaviors under the premise that their risk perception could be modified with improvements in disease-associated knowledge, skills, and self-confidence in condom use. However, after a 6-month trial period in young AAs, no differences in sexual health risk behaviors were noted between the intervention and control groups. ${ }^{13}$ This finding suggests that knowledge alone is not enough to promote risk perception and protective sexual behaviors in young people. ${ }^{14-16}$ Furthermore, low self-perceived risk or "optimistic bias" about HIV infection has been noticed more in adolescents than adults. ${ }^{17-20}$ It is thus essential to examine the impact of social environments on the development of risk perception.

Ecodevelopmental theory is considered the best approach to studying youth-behavior development, because it includes social context and can examine influences of social determinants in one big picture..$^{21,22}$ This study explored associations between social determinants and behavioral and self-perceived $\mathrm{STD} / \mathrm{HIV}$-infection risks. The aim of the study was to examine the level of agreement between young AAs' actual and self-perceived risk of contracting STDs/HIV within their social contexts utilizing an ecodevelopmental framework. ${ }^{23}$ Hypotheses tested were that young AAs have an unrealistic optimism of not contracting STDs/HIV, and that social factors associated with parenting functions play essential roles in modifying youths' epidemiological risk, but not their selfperceived risk.

\section{Ecodevelopmental theory: a contextual framework for examining HIV-risk behavior}

Ecodevelopmental theory was first proposed by Szapocznik and Coatsworth in $1999,{ }^{21,22}$ extending the social ecological model with a focus on the structure and organization of youths' social context and incorporating potential interactions and time factors. ${ }^{23,24}$ The theory has four systems: microsystem, mesosystem, exosystem, and macrosystem. Unlike the social ecological model, however, ecodevelopmental theory posits that parents and family function are the most essential elements to a youth's behavioral development, while social contexts in different systems can interact with one another to impact a youth's behavior directly and indirectly. In general, ecodevelopmental theory focuses on interactions within and between social systems that impact a young person's behavioral development.

The microsystem represents the contexts in which young people interact most directly, including peer groups, school, religion, and neighborhood. ${ }^{25-28}$ These social contexts have the most powerful social influence on the adolescent. However, family function and the connection between parents and their children are the most fundamental elements for a youth's behavioral development. ${ }^{29-32}$ The mesosystem is composed of all relationships developed from the microsystem and the impact of a sequence of events on youth. For example, the practice of parents' involvement in a youth's social environment could prevent the acquisition of risky sexual behaviors from peers. ${ }^{33-36}$ Similarly, parental support can reduce the likelihood of depression and delinquency in youth. ${ }^{37}$ The exosystem includes external factors that impact the microsystem but not the youth directly, eg, a coparent in a single-mother household can undermine the youth's mental health through conflicts with the mother. ${ }^{38}$ Conversely, the macrosystem embraces a broader social environment, such as policy and culture. The macrosystem is considered acculturation that tends to weaken family function and increases youths' likelihood of contracting HIV. ${ }^{39}$

Several studies have suggested that only the ecodevelopmental framework provides adequate guidance for the 
development of behavior-intervention programs to prevent youths from contracting HIV, and may be useful for discovering processes influencing youths' self-perception. ${ }^{40-43}$ The first health-intervention program to apply ecodevelopmental theory was "Familias Unidas". ${ }^{40}$ This program aimed at strengthening parenting skills and building a strong parentsupport network for first-generation immigrant Hispanic parents, and resulted in the prevention of young Hispanic Americans adopting risky behaviors. Specifically, Prado et $\mathrm{al}^{22}$ found that the acculturation gap between first- and second-generation Hispanic immigrants was indirectly associated with early sex debut and youths' substance use resulting from weakened family functioning. While it is known that adolescents tend to develop their autonomy by replacing parental ties with strong peer connections, ${ }^{41-43}$ it is still unknown what role parenting styles, family structure, and other social factors play in modifying the internalization of a child's beliefs and appraisal of risk. The ecodevelopmental framework can thus be a powerful instrument to examine risk and protective processes in a youth's behavioral development under the influence of culture, and explore the relationships between a youth's risk perception, parenting styles, family structure, and other social contexts.

\section{Methods}

\section{Study design and participants}

This was a retrospective cross-sectional study to compare young AAs' self-perceived risk of contracting STDs/HIV vs their actual risk from an epidemiological standpoint and to examine the associations between social determinants related to STD/HIV-infection risk. The National Longitudinal Study of Adolescent Health database (Add Health database) ${ }^{44,45}$ was designed to sample nationally representative adolescents in grades 7-12 from 1994 to 1995, and comprised a variety of the young people's social, economic, psychological, and physical well-being domains, including family, peers, romantic relationships, and household arrangement. The first wave (wave I) of Add Health data was used for the current study, and included 1,619 AA youths aged 14-18 years. The choice of wave I was predicated on the fact that it focused on the forces that influence adolescents' health and risk behaviors, including personal traits, families, friendships, romantic relationships, peer groups, schools, neighborhoods, and communities, and thus offered a contextual framework for the application of ecodevelopmental theory. Consequently, the current research lays a strong foundation for follow-up studies to explore the impact of adolescents' experiences and changes in behavior during transition to adulthood using waves II-IV.

\section{Measures and operationalization}

The primary goal of this study was to gain understanding about young AAs' perceived risk of contracting STDs/HIV. We modeled an "epidemiological index" of STD/HIV risk after those developed by Mgbere et $\mathrm{a}^{46}$ to serve as the actual risk and a "gold standard" for comparing the youths' selfperceived risk status. The following assumptions were made: 1) that self-perception of risk among AA youths serve as an indicator for understanding their susceptibility to contracting STD/HIV infections and a precursor to behavioral change, which could determine future decision-making regarding risk-taking; 2) that AA youths who have practiced high-risk behaviors in the past would perceive themselves as having moderate/high risk of contracting STDs/HIV; 3) that AA youths who had not practiced high-risk behaviors in the past would perceive themselves as having no/low risk of contracting STDs/HIV; and 4) that self-perceived risk among AA youths is a direct reflection of their epidemiological risk (actual risk) of contracting STDs/HIV.

The epidemiological index in the current study was a composite score of eight health-related variables identified based on a literature review. These variables were age at first sexual debut (score 1-4), HIV infection (yes/no, score $1 / 0$ ), having tested for HIV (yes/no, score 1/0), number of STD infections (score 1-4), birth-control methods at first sex (score 1-4), birth-control methods at recent sex (score $1-4)$, frequency of condom use (score 1-5), and giving sex in exchange for drugs/money (yes/no, score 1/0). A composite score that summarized each participant's responses for the eight variables was computed $(n=1,619$, mean $16.31 \pm 0.15$; range 5-24) and represented AA youths' epidemiological risk index. The average score obtained was used to categorize the study participants' epidemiological risk into two risk groups: no/low risk (mean score and above) and moderate/high risk (below mean score). Epidemiological risk was used as proxy for actual risk status based on the cross-sectional study design, and thus served as the gold standard for comparing respondents' self-perceived risk. Highest and lowest scores represented the lowest and highest epidemiological risk, respectively, of contracting STDs/HIV.

The self-perceived risk index was developed using two questions: What do you think the chances are that you will get HIV? (almost certain, 1; a good chance, 2; a 50-50 chance, 3; some chance/but probably not, 4; almost no chance, 5); What 
do you think the chances are that you will get AIDS? (very high, 1; high, 2; low, 3; very low, 4; and none, 5). A composite score of each participant's responses to the two questions was computed ( $n=1,611$, mean $8.60 \pm 0.05$, range $2-10)$, and represented AA youths' self-perceived risk index. The average score obtained was set as the threshold for determining participants' self-perceived risk levels, with mean scores and above representing no/low risk and below mean scores representing moderate/high risk. As such, highest and lowest scores represented the lowest and highest self-perceived risk, respectively, of contracting STDs/HIV.

The congruence of epidemiological and self-perceived risks was defined as a measure of accuracy. This implied that the youth's self-perception was the same as the epidemiological risk of contracting STDs/HIV. Both the accuracy and level of agreement of the two independent measures were examined, and represented the congruence of the selfperceived and epidemiological risk indices after controlling for random agreement. Independent factors in this study were selected using the ecodevelopmental framework to match the various systems (microsystem, mesosystem, exosystem, and macrosystem) ${ }^{47}$ Since the theoretical framework emphasizes parenting style/family functions as the prime factors influencing youth's behavioral development, the following variables were included: parents' love, parents' involvement, parents' socioeconomic status, parents' attitude toward youth's use of birth control, and household arrangement. To represent other social context domains that could have a high influence on the individual's sexual behavioral development and awareness about the risk of HIV infection, peers, school, neighborhood, and religion were also considered.

\section{Ecodevelopmental systems}

Although ecodevelopmental theory is an inclusively theoretical framework, there is no precise definition for each system of the model. This study selected the issues, risk, and protective processes that were found to be associated with AA youths and STD/HIV infection from the literature review. A summary of the various systems and the associated variables in the current study is given in the following sections. For a more detailed explanation of the ecodevelopmental theoretical framework related to this study, please refer to Li et al. ${ }^{47}$

\section{Microsystem}

Domains of the microsystem (parents, peers, school, living environment [neighborhood], and religion) are considered the most direct social context contacts for young AAs. ${ }^{48,49}$ Due to the high prevalence of single-mother households in
AA families, ${ }^{50,51}$ the functions of the father and the mother were assessed independently to determine influences from each on the youth's STD/HIV-related behavior.

\section{Mesosystem}

We believed that the physical involvement of the parents is a major process in the mesosystem. Such activities as having good communication with parents, participating in religious activities with parents, talking about what they are doing in school and their grades with parents, and parents' expectations of level of education of the youth were the processes considered in association with the mesosystem..$^{31,35,36,48}$

\section{Exosystem}

Parents' attitudes or values can have an indirect impact on adolescents' beliefs and behavioral development. ${ }^{32,52}$ Subcultures of AA population or experience of the parents have significant influences on the exosystem. For example, a youth's use of the birth-control method used by his or her parents is considered part of the culture of AA communities. This factor may modify the parents' function, but does not directly influence the young individual..$^{52}$

\section{Macrosystem}

Policy impact (public assistance) and socioeconomic status have been reported to be intertwined and to modify family function profoundly. ${ }^{53,54}$ In the current study, the processes considered under the macrosystem were types of parents, weekly working hours, whether working outside the home, and receipt of public assistance.

\section{Statistical analyses}

We conducted Rao-Scott $\chi^{2}$ analyses using SAS Proc SurveyFreq with weighted Add Health data. This allowed for design-adjusted estimates to compare levels of associations within independent variables, and across outcome variables (self-perceived and epidemiological risks) with independent variables. Cohen's $\kappa$-statistic was used to examine the concordance of the individual's risk status between epidemiological and self-perceived risks. Cohen's $\kappa$-coefficient estimated the level of agreement and range from 0 to 1 , representing no agreement to perfect agreement. Cohen's $\kappa$-coefficient was calculated based on the equation $\kappa=\left(\mathrm{A}_{\mathrm{obs}}-\mathrm{A}_{\mathrm{ch}}\right) /\left(\mathrm{N}-\mathrm{A}_{\mathrm{ch}}\right)$, where $A_{\text {obs }}$ is observed agreement between self-perceived and epidemiological risk levels, $A_{c h}$ total agreement expected by chance, and $\mathrm{n}$ total sample size.

We conducted series of multivariable regression analyses applying the stepwise technique with a forward-selection 
option to select independent variables to enter the models, because we were interested in the most parsimonious models with the minimum number of independent variables that would predict outcome variables. This approach allowed for simultaneous adjustment of associated covariates and potential confounders in the models. The five multivariable models evaluated were: model 1, epidemiological risk of contracting $\mathrm{STD} / \mathrm{HIV}$; model 2, self-perceived risk of contracting STD/ HIV; model 3, accuracy of risk assessment (match between self-perceived risk and epidemiological risk assessments) unadjusted for self-perceived risk; model 4, epidemiological risk of contracting STD/HIV after adjustment for self-perceived risk; and model 5, accuracy of epidemiological risk of contracting STD/HIV after adjusting for self-perceived risk.

Adjusted ORs (aORs) with 95\% CIs were computed for applicable outcomes and associated independent variables. Regression diagnostics yielded no evidence of multicollinearity or overly influential outliers in any of the five models. Finally, we conducted a series of model goodness-of-fit tests comprising the Akaike information criterion, Schwarz criterion, likelihood ratio, Wald test, and concordance statistic ( $C$-index) tests. All statistical tests performed were two-tailed, with $P=0.05$ used as the significance threshold. All analytical computations and estimates were carried out using design-adjusted base weights to compensate for unequal probabilities of selection and nonresponse. All data management and statistical analyses were carried out using SAS 9.4 (SAS Institute Inc., Cary, NC, USA).

\section{Ethics statement}

This study received approval from the University of Houston Committee for the Protection of Human Subjects. We used an existing secondary data set with no identifiers linking individuals' information to the data and thus received an exempt status approval from the committee.

\section{Results}

\section{Characteristics of study population}

Characteristics of AA youths in our study population are presented in Table 1. A total of $61.8 \%$ of AA youth respondents in the Add Health database were 14-17 years old and 34.9\% 18 years old and above. Among the target population, 50\% were females and $2.5 \%$ a sexual minority. In terms of family structure, eight in ten youths were living with their biological mothers, while three in ten lived with their biological father. About half the young AAs surveyed knew their biological fathers, but did not live with them.
Among the young AAs, 44\% had no sexual experience, $10 \%$ had their first sex before 10 years of age, $35 \%$ had their first sex during ages 10-16 years, and 11\% had their first sexual experience during ages 16-20 years. As of the survey period, two of the AA youths were already HIV-infected, and $90 \%$ of those surveyed had never been tested for HIV. About $2 \%$ of the youths were having sex in exchange for drugs or money, while $10 \%$ had at least one STD. Approximately $40 \%$ stated that they used other types of birth control or did not use any forms of birth control during their first or most recent sexual intercourse. About $95 \%$ of those who had any form of birth control used a condom at either their first or most recent sexual intercourse.

In terms of the accuracy of self-perceived risk, $55.72 \% \pm 1.67 \%$ of the young AAs accurately estimated their risk of contracting STDs/HIV. After taking the random agreement into consideration, however, Cohen's $\kappa$-test indicated that the young AAs in fact had low congruence between their self-perception and actual risk level (epidemiological risk), with an overall $\kappa$-coefficient of 0.1443 (95\% CI 0.1037-0.1928).

Table 2 presents associations between factors identified using ecodevelopmental theory and both self-perceived and epidemiological risk indices. It was observed that in general, the majority of AA youths perceived themselves to be at relatively no/low risk of contracting STDs/HIV, with figures ranging from $50.2 \%$ for those who had been tested for HIV in the past to $90.1 \%$ for those who used condoms during their sexual debut. In contrast, the epidemiological risk assessment indicated that based on their sexual behaviors and activities, they were mostly (100\%) at moderate/high risk of contracting STDs/HIV (Table 3). For instance, youths who had been tested for HIV in the past were about 50\% split (no/low risk vs moderate/high risk; $\chi^{2}=25.36 ; P<0.0001$ ) in their self-assessment of risk compared to the epidemiological risk assessment, whereas as much as $87.4 \%$ were reported to be at moderate/high risk compared to only $12.6 \%$ at no/ low epidemiological risk $\left(\chi^{2}=53.01, P<0.0001\right)$. For those who had never been tested for STDs/HIV, their risk level for contracting STDs/HIV increased significantly by $20 \%$ when the epidemiological assessment was conducted. Although the epidemiological risk assessment indicated that $100 \%$ of AA youths who had had their sexual debut were at moderate/high risk of contracting STDs/HIV, their self-assessment indicated that only $39.2 \%, 43.6 \%$, and $33.9 \%$ of those aged $<10,10-15$, and 16-20 years at sexual debut were at moderate/high risk of contracting STDs/HIV, respectively. Furthermore, more 
Table I Characteristics of African American youths in the study population

\begin{tabular}{|c|c|c|c|c|c|}
\hline Characteristic & $\mathbf{n}$ & Weighted $\mathbf{n}$ & Percentage (SD) & $\chi^{2}(d f)^{\#}$ & $P$-value \\
\hline Age-group (years) & & & & $739.62(2)$ & $<0.0001 * * * *$ \\
\hline $10-13$ & 72 & 120,849 & $3.31(0.47)$ & & \\
\hline $14-17$ & 1,028 & $2,256,803$ & $61.80(1.32)$ & & \\
\hline$\geq 18$ & 519 & $\mathrm{I}, 274,348$ & $34.89(1.25)$ & & \\
\hline Biological mother & & & & $\mathrm{I}, 078.46(2)$ & $<0.0001 * * * *$ \\
\hline Not known & 26 & 74,572 & $2.05(0.46)$ & & \\
\hline Known & 203 & 551,897 & $15.15(1.15)$ & & \\
\hline Living with biological mother & 1,388 & $3,016,506$ & $82.80(I .2 I)$ & & \\
\hline Biological father & & & & $257.8 \mathrm{I}(2)$ & $<0.0001 * * * *$ \\
\hline Not known & 194 & 501,515 & $13.79(1.10)$ & & \\
\hline Known & 819 & $1,957,921$ & $53.85(1.53)$ & & \\
\hline Living with biological father & 602 & $1,176,562$ & $32.36(1.35)$ & & \\
\hline Sex & & & & $0.02(\mathrm{I})$ & $0.8797^{\mathrm{NS}}$ \\
\hline Female & 846 & $\mathrm{I}, 817,50 \mathrm{I}$ & $49.77(1.54)$ & & \\
\hline Male & 773 & $\mathrm{I}, 834,499$ & $50.23(1.54)$ & & \\
\hline Sexual orientation & & & & $983.55(I)$ & $<0.000 I^{* * * * *}$ \\
\hline Majority (heterosexual) & $\mathrm{I}, 583$ & $3,560,170$ & $97.49(0.47)$ & & \\
\hline Minority (homosexual/bisexual) & 36 & 91,830 & $2.5 I(0.47)$ & & \\
\hline Sexual debut (years) & & & & $404.24(3)$ & $<0.0001 * * * *$ \\
\hline$<10$ & 153 & 372,725 & $10.21(0.93)$ & & \\
\hline $10-15$ & 510 & $1,262,493$ & $34.57(\mathrm{I} .44)$ & & \\
\hline $16-20$ & 176 & 393,246 & $10.77(0.89)$ & & \\
\hline Never had sexual intercourse & 780 & $\mathrm{I}, 623,537$ & $44.46(\mathrm{I} .44)$ & & \\
\hline HIV infection & & & & $\mathrm{I}, 052.28(\mathrm{I})$ & $<0.000 I^{* * * * *}$ \\
\hline No infection & 1,615 & $3,641,058$ & $99.81(0.13)$ & & \\
\hline Infected & 2 & 6,860 & $0.19(0.13)$ & & \\
\hline HIV testing & & & & $599.49(\mathrm{I})$ & $<0.000 I^{* * * * *}$ \\
\hline Tested & 141 & 366,360 & $10.08(0.98)$ & & \\
\hline Never tested & 1,474 & $3,269,809$ & $89.92(0.98)$ & & \\
\hline Birth control during first sex & & & & $457.40(3)$ & $<0.0001 * * * *$ \\
\hline Never had sexual intercourse & 780 & $1,623,537$ & $44.67(\mathrm{I} .44)$ & & \\
\hline Condom & 536 & $\mathrm{I}, 223,387$ & $33.66(I .4 I)$ & & \\
\hline Other birth control & 16 & 44,572 & $1.23(0.33)$ & & \\
\hline None & 282 & 743,101 & $20.45(1.29)$ & & \\
\hline Birth control during recent sex & & & & $386.43(3)$ & $<0.0001 * * * *$ \\
\hline Never had sexual intercourse & 780 & $\mathrm{I}, 623,537$ & $45.04(1.45)$ & & \\
\hline Condom & 518 & $1,184,020$ & $32.85(1.42)$ & & \\
\hline Other birth control & $4 I$ & 113,044 & $3.14(0.59)$ & & \\
\hline None & 261 & 683,805 & $18.97(1.26)$ & & \\
\hline Frequency of condom use & & & & $1,053.350(4)$ & $<0.0001 * * * *$ \\
\hline Never had sexual intercourse & 780 & $\mathrm{I}, 623,537$ & $44.46(1.44)$ & & \\
\hline Most of the time & 32 & 94,968 & $2.60(0.57)$ & & \\
\hline Half the time & 48 & $126,20 \mid$ & $3.46(0.55)$ & & \\
\hline Sometimes & 41 & 121,078 & $3.32(0.57)$ & & \\
\hline Never & 718 & $\mathrm{I}, 686,214$ & $46.17(1.47)$ & & \\
\hline Giving sex in exchange for drugs/money & & & & $919.76(\mathrm{I})$ & $<0.0001 * * * *$ \\
\hline No & $\mathrm{I}, 582$ & $3,543,24 I$ & $98.09(0.43)$ & & \\
\hline Yes & 25 & 69,171 & $1.91(0.43)$ & & \\
\hline Frequency of attending religious service & & & & $249.6 \mathrm{I}(3)$ & $<0.0001 * * * *$ \\
\hline Once a week or more & 803 & $1,613,945$ & $44.38(\mathrm{I} .46)$ & & \\
\hline Once a month or more & 357 & 824,134 & $22.66(1.25)$ & & \\
\hline Less than once a month & 178 & 427,797 & $11.76(0.97)$ & & \\
\hline Never & 277 & 771,123 & $21.20(1.28)$ & & \\
\hline Importance of religion & & & & $443.17(\mathrm{I})$ & $<0.0001 * * * *$ \\
\hline Important & 1,390 & $3,029,199$ & $83.24(1.18)$ & & \\
\hline Not important & 225 & 609,805 & $16.76(1.18)$ & & \\
\hline
\end{tabular}


Table I (Continued)

\begin{tabular}{|c|c|c|c|c|c|}
\hline Characteristic & $\mathbf{n}$ & Weighted n & Percentage (SD) & $\chi^{2}(d f)^{\#}$ & $P$-value \\
\hline Gone to religious service with mother & & & & $348.73(2)$ & $<0.000 I^{* * * * *}$ \\
\hline No mother & 77 & 223,632 & $6.15(0.8 I)$ & & \\
\hline No & 779 & $\mathrm{I}, 852,535$ & $50.94(1.48)$ & & \\
\hline Yes & 757 & $\mathrm{I}, 560,77 \mathrm{I}$ & $42.91(1.42)$ & & \\
\hline Gone to religious service with father & & & & $294.67(2)$ & $<0.000 I^{* * * * *}$ \\
\hline No father & 822 & $2,031,395$ & $55.74(1.48)$ & & \\
\hline No & 490 & $\mathrm{I}, 047,520$ & $28.74(1.37)$ & & \\
\hline Yes & 303 & 565,356 & $|5.5|(1.02)$ & & \\
\hline Number of sexually transmitted diseases & & & & $947.02(3)$ & $<0.0001 * * * *$ \\
\hline More than one & 20 & 47,712 & $\mathrm{I} .3 \mathrm{I}(0.3 \mathrm{I})$ & & \\
\hline One & 62 & 157,312 & $4.3 \mathrm{I}(0.6 \mathrm{I})$ & & \\
\hline None & 756 & $1,822,17 \mid$ & $49.91(1.49)$ & & \\
\hline Never had sexual intercourse & 780 & $1,623,537$ & $44.47(1.44)$ & & \\
\hline
\end{tabular}

Notes: From I,619 observations. "Rao-Scott (allows for design-adjusted estimates); *****P<0.000I.

Abbreviation: NS, not significant.

than half of those who had contracted STDs perceived themselves to be at no/low risk, while in contrast they were $100 \%$ at moderate/high risk of contracting STDs/HIV, given the epidemiological assessment.

Table 3 shows levels of agreement between self-perceived risk and epidemiological risk by each identified ecodevelopmental variable based on Cohen's $\kappa$-statistic. In general, levels of agreement between both risk measures across most of the independent variables was not significant $(P>0.05)$. Low levels of agreement were noted only between self-perceived and epidemiological risk measures for the independent variables "feel love of mother" $(\kappa=0.143,95 \%$ CI $0.098-0.188$; $P=0.052$ ), "feel like talking to mother" ( $\kappa=0.138,95 \% \mathrm{CI}$ $0.093-0.182 ; P=0.053)$, and "closest friends know the rhythm method of birth control" ( $\kappa=0.148,95 \%$ CI $0.104-0.191$; $P=0.054)$. These figures generally denoted very low agreement between the assessment methods, and confirmed that the majority of AA youths tended to underrate their STD/ HIV risk levels through self-perception compared to the epidemiologically assessed risk levels.

\section{Multivariate regression model}

The multivariate regression models of epidemiological risk index, self-perceived risk index, and accuracy of assessments are shown in Table 4. Based on ecodevelopmental theory, eight independent variables (feeling like talking to the mother, no trouble getting along with teachers, teachers treat students fairly, close friends know how to use condom correctly, age-group, sex, mother's attitude toward respondent's use of birth control, and mother's disapproval of having sex at this time of life) were significantly $(P \leq 0.01)$ associated with epidemiological risk and resulted in good model fit (model 1). On the other hand, some of the factors identified using the ecodevelopmental framework were neither good predictors of individuals' self-perceived risk nor accuracy of individuals' risk assessments (models 2, 3, and 5). Model 3 indicated that feeling like talking to the mother (aOR 1.23, $P=0.020$ ) was associated with better accuracy of risk assessment and that getting older (aOR $0.74, P=0.002$ ) was related to lower accuracy of risk assessment. After controlling for self-perceived risk, however, the impact of the mother in the microsystem (feel like talking to mother, aOR, 1.28; $P=0.005$ ) and exosystem (mother's negative attitude toward youth's condom use, aOR $0.83 ; P=0.037$ ) became more significantly related to better accuracy of risk assessment (model 5). However, the mother's negative attitude toward the respondent's use of birth control and growing older (10 years and above) were related to accurate risk assessment.

Finally, model 4 was considered the best model, based on goodness-of-fit indices $(C=0.785)$. Model 4 specified essential relationships between independent variables from the different ecodevelopmental systems and AA youths' epidemiological risk after taking individual self-perceived risk into consideration. For example, better interaction with the mother (such as feeling like talking to mother, aOR 0.76; $P=0.002$ ), close friends having adequate knowledge of condom use (aOR 0.50, $P<0.0001$ ), mother's disapproval of sexual initiation (OR $0.58, P<0.0001$ ), feeling of having trouble getting along with teachers (no trouble, aOR 0.76; $P=0.002$ ), and feeling that teachers treat students unequally (equal treatment, aOR $0.80 ; P=0.0001$ ) were associated with lower epidemiological risk of contracting STDs/HIV. On the 


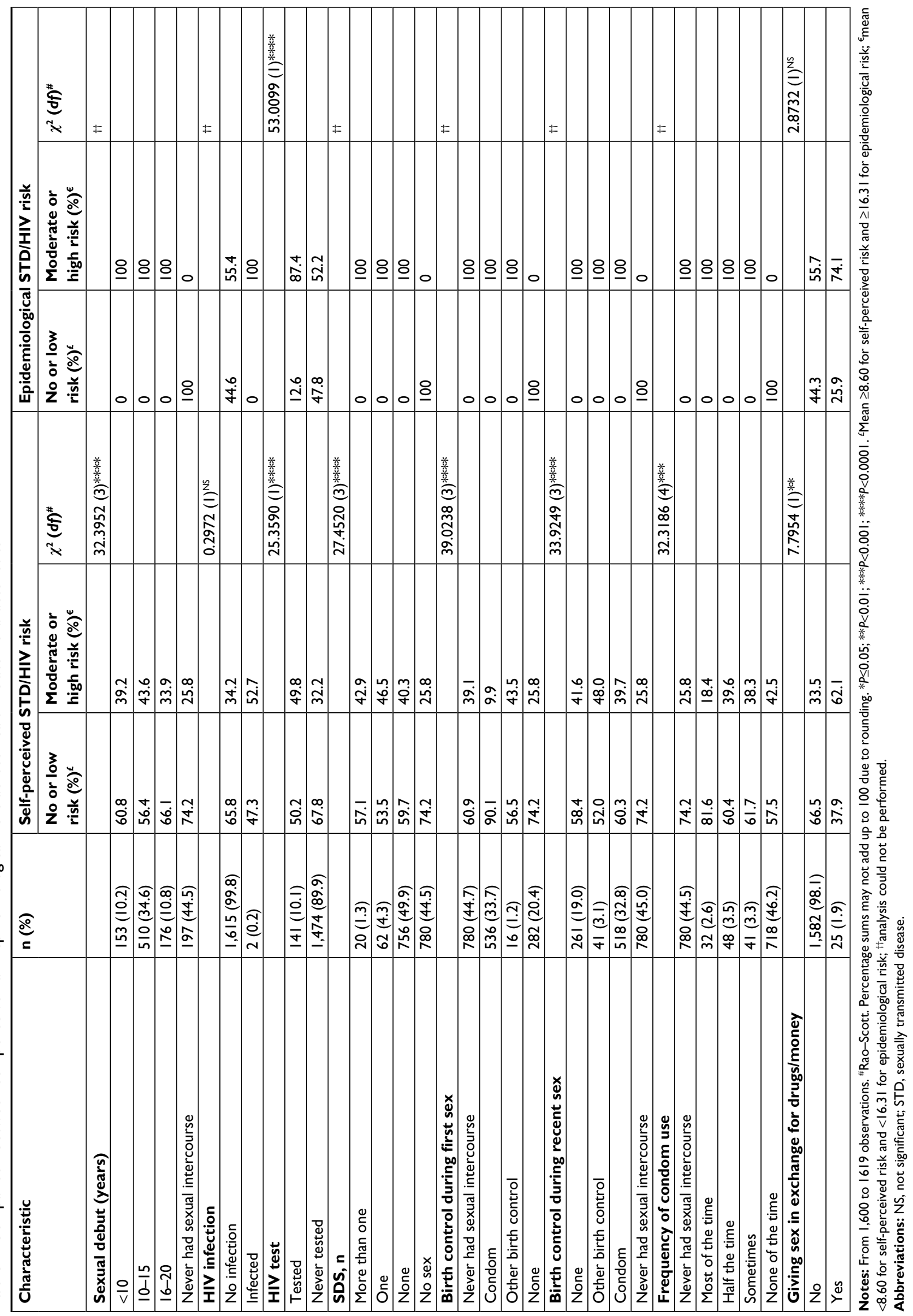


Table 3 Agreement $(\kappa)$ test between self-perceived and epidemiological risk after controlling for the individual variable

\begin{tabular}{|c|c|c|c|c|c|}
\hline Variable & $\begin{array}{l}\text { Effective } \\
\text { size }(n)\end{array}$ & k-coefficient & $95 \% \mathrm{Cl}$ & $\chi^{2}(d f)^{\#}$ & P-value \\
\hline Mother receives public assistance & 1,594 & 0.1470 & $0.1023-0.1917$ & $3.7540(2)$ & 0.1530 \\
\hline Feel love of mother & 1,617 & 0.1430 & $0.0984-0.1875$ & $7.7097(3)$ & $0.0524 *$ \\
\hline Feel care from mother & 1,617 & 0.1429 & $0.0983-0.1875$ & $5.2824(3)$ & 0.1522 \\
\hline Feel close to mother & 1,617 & 0.1398 & $0.0952-0.1844$ & $5.2416(3)$ & 0.1549 \\
\hline Feel like talking to mother & 1,618 & 0.1376 & $0.0929-0.1823$ & $7.6968(3)$ & $0.0527^{*}$ \\
\hline Talk to mother about school grades & 1,613 & 0.1462 & $0.1017-0.1907$ & $3.7517(2)$ & 0.1532 \\
\hline Talk to mother about things one is doing at school & 1,613 & 0.1465 & $0.1020-0.1910$ & $4.1518(2)$ & 0.1254 \\
\hline Mother's disappointment at child's not graduating from high school & 1,619 & 0.1442 & $0.0998-0.1887$ & $3.8598(3)$ & 0.2770 \\
\hline Mother's disappointment at child's not graduating from college & 1,619 & 0.1449 & $0.1005-0.1893$ & $5.5794(3)$ & 0.1340 \\
\hline Father receives public assistance & 1,613 & 0.1462 & $0.1019-0.1906$ & $0.104 I(2)$ & 0.9493 \\
\hline Feel love of father & 1,616 & 0.1451 & $0.1007-0.1894$ & $1.5739(3)$ & 0.6653 \\
\hline Feel care from father & 1,617 & 0.1422 & $0.0979-0.1865$ & $1.7054(3)$ & 0.6357 \\
\hline Feel close to father & 1,617 & 0.1412 & $0.0969-0.1855$ & $1.8035(3)$ & 0.6357 \\
\hline Feel like talking to father & 1,616 & 0.1446 & $0.1003-0.1890$ & $0.1890(3)$ & 0.7650 \\
\hline Talk to father about school grade & 1,615 & 0.1463 & $0.1019-0.1908$ & $1.5005(2)$ & 0.4722 \\
\hline Talk to father about things one is doing at school & 1,615 & 0.1466 & $0.1022-0.1911$ & $0.0017(2)$ & 0.9992 \\
\hline Father's disappointment at child's not graduating from high school & 1,618 & 0.1451 & $0.1008-0.1895$ & $3.7718(3)$ & 0.2872 \\
\hline Father's disappointment at child's not graduating from college & 1,618 & 0.1491 & $0.1048-0.1933$ & $4.6290(3)$ & 0.2011 \\
\hline Occupation of mother & 1,599 & 0.1511 & $0.1067-0.1954$ & $7.7788(4)$ & 0.1000 \\
\hline Weekly working hours of mother & 1,612 & 0.1498 & $0.1053-0.1942$ & $7.6207(5)$ & 0.1784 \\
\hline Mother works outside home & $\mathrm{I}, 554$ & 0.1497 & $0.1046-0.1948$ & $8.5607(4)$ & 0.0731 \\
\hline Biological mother & 1,617 & 0.1469 & $0.1024-0.1913$ & $2.4737(2)$ & 0.2903 \\
\hline Biological father & 1,615 & 0.1503 & $0.1063-0.1943$ & $1.3346(2)$ & 0.5131 \\
\hline No trouble getting homework done & 1,617 & 0.1364 & $0.0919-0.1808$ & $8.7407(4)$ & 0.0679 \\
\hline Trouble getting along with teachers & 1,617 & 0.1453 & $0.1010-0.1896$ & $1.8173(4)$ & 0.7693 \\
\hline Feel close to people at school & 1,616 & 0.1482 & $0.1037-0.1927$ & $2.0863(2)$ & 0.3523 \\
\hline Teachers treat students fairly & 1,617 & 0.1398 & $0.0952-0.1843$ & $1.5616(2)$ & 0.4580 \\
\hline Grade-point average & 1,619 & 0.1393 & $0.0952-0.1835$ & $3.8295(3)$ & 0.2805 \\
\hline Occupation of father & 1,606 & 0.1490 & $0.1046-0.1934$ & $5.4582(4)$ & 0.2434 \\
\hline Weekly working hours of father & 1,616 & 0.1484 & $0.104 I-0.1928$ & $3.5969(5)$ & 0.6088 \\
\hline Father works outside home & $\mathrm{I}, 588$ & 0.1485 & $0.1039-0.1932$ & $3.4322(4)$ & 0.4883 \\
\hline Importance of religion & 1,615 & 0.1468 & $0.1023-0.1913$ & $4.7638(3)$ & 0.1899 \\
\hline Frequency of attending religious services & 1,615 & $0.150 I$ & $0.1055-0.1946$ & $0.1468(1)$ & 0.1626 \\
\hline Gone to religious service with mother & 1,613 & 0.1446 & $0.1000-0.1891$ & $4.1249(2)$ & 0.1271 \\
\hline Gone to religious service with father & 1,615 & 0.1465 & $0.1021-0.1909$ & $0.4696(2)$ & 0.7907 \\
\hline Householder & 1,619 & $0.148 \mid$ & $0.1040-0.1923$ & $3.0365(4)$ & 0.5517 \\
\hline Close friends know how to use condom correctly & 1,606 & 0.1424 & $0.0986-0.1862$ & $3.5323(2)$ & 0.1710 \\
\hline Closest friends know the rhythm method of birth control & 1,600 & 0.1476 & $0.1042-0.1911$ & $5.8233(2)$ & $0.0544 *$ \\
\hline Closest friends know the withdrawal method of birth control & 1,606 & 0.1460 & $0.1018-0.1901$ & $\mathrm{I} .5476(2)$ & 0.4613 \\
\hline Perception of home safety & $\mathrm{I}, 60 \mathrm{I}$ & 0.1507 & $0.1064-0.1951$ & $0.0979(\mathrm{I})$ & 0.7544 \\
\hline How well dwelling is kept & $\mathrm{I}, 597$ & 0.1510 & $0.1067-0.1953$ & $0.8168(2)$ & 0.6647 \\
\hline Biological sex & 1,619 & 0.1353 & $0.0905-0.1801$ & $1.6342(1)$ & 0.2011 \\
\hline Sexual orientation $\$$ & 1,619 & 0.1456 & $0.1012-0.1899$ & $2.5635(I)$ & 0.1094 \\
\hline Mother's attitude toward respondent's use of birth control & 1,613 & 0.0972 & $0.0533-0.1412$ & $1.6713(2)$ & 0.4336 \\
\hline Father's attitude toward respondent's use of birth control & 1,616 & 0.1181 & $0.0737-0.1626$ & $1.5993(2)$ & 0.4495 \\
\hline If having sex at this time in your life, mother would disapprove & 1,612 & 0.1146 & $0.07 \mid 4-0.1577$ & $2.6177(2)$ & 0.2701 \\
\hline $\begin{array}{l}\text { If having sexual intercourse with steady partner, mother would } \\
\text { disapprove }\end{array}$ & 1,612 & 0.1010 & $0.0573-0.1447$ & $4.7402(2)$ & 0.0935 \\
\hline If having sex at this time in your life, father would disapprove & 1,615 & 0.1249 & $0.0815-0.1683$ & $2.8609(2)$ & 0.2392 \\
\hline $\begin{array}{l}\text { If having sexual intercourse with steady partner, father would } \\
\text { disapprove }\end{array}$ & 1,615 & 0.1247 & $0.0809-0.1684$ & $3.9768(2)$ & 0.1369 \\
\hline Age-group ${ }^{*}$ & 1,619 & 0.1241 & $0.0804-0.1678$ & $2.3668(2)$ & 0.3062 \\
\hline
\end{tabular}

Notes: From I,554 to I,619 observations. "\#ao-Scott; " majority (heterosexuality) vs minority (homosexuality or bisexuality); ${ }^{*} \leq 13$ years, $14-17$ years, and $\geq 18$ years; $* P<0.05$. 


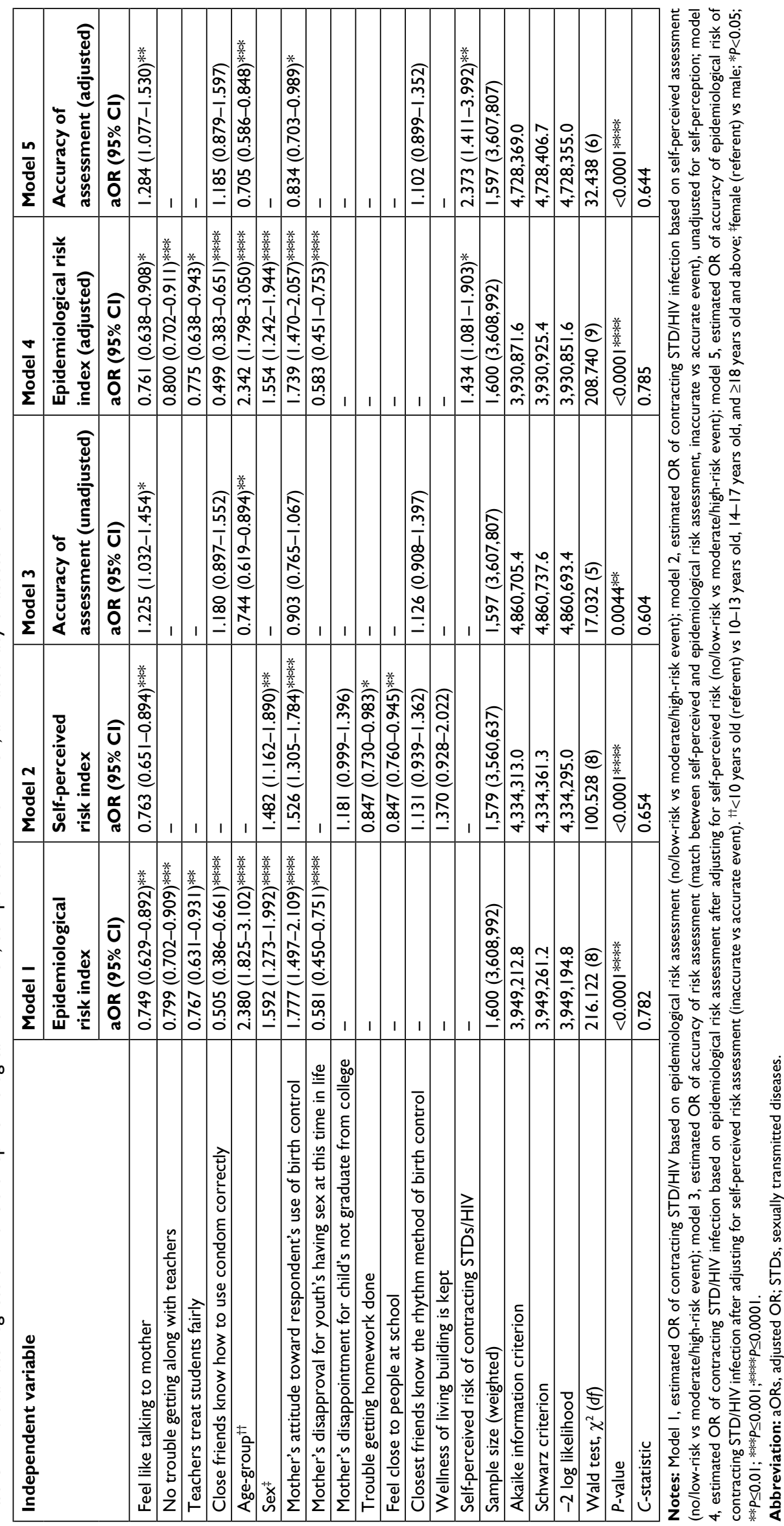


other hand, being an AA male (aOR 1.55, $P=0.0001$ ), stronger negative attitude of mother toward AA youth's use of birth control (aOR 1.74, $P<0.0001)$, being older $(10+$ years, aOR $2.34 ; P<0.0001)$ and having a moderate/high self-perception of risk (aOR 1.43, $P<0.05$ ) were positively associated with higher epidemiological risk of contracting STDs/HIV.

\section{Discussion}

Perception of STD/HIV risk is the main driving force for HIV testing. Inaccurate self-perception or objective perception of risk can impede HIV diagnosis and treatment. Our study aimed to uncover relationships between self-perceived risk and actual (epidemiological) risk of STDs/HIV in AA youth and the influence of ecodevelopmental system measures, such as parenting styles, family structure, and other social factors on the accuracy of risk assessments.

Findings from our study indicate that significant discordance exists between self-perceived and epidemiological risk assessment among young AA adolescents. Although the majority of AA youths across the various levels of the independent variables considered themselves (self-perception) to be at no/low risk, when set against actual risk (epidemiological risk) assessment, we noted that they were all at moderate/high risk of contracting STDs/HIV. Similar differences between self-perceived and actual risks have been reported in various subpopulations and study settings. ${ }^{14,19,29,30,46,47,55-57}$ Our study finding implies that STD/HIV-risk perceptions among AA adolescents are highly inaccurate, which may be due to the influence of other factors not directly related to sexual behavior and/or to some extent the use of general and specific indicators in the two risk measures. This optimistic bias among young AAs threatens their health status, ${ }^{58-60}$ especially when weighed against the high prevalence of HIV infection reported in this population. 1,59,60

None of the current study assumptions was met. Consequently, our results point to the need for interventions that may help modify self-perceived STD/HIV risk and align it with epidemiological risk. Multivariate regression analysis of determinants of the risk assessments in our study offers insights into how both self-perceived and epidemiological risk may be modified.

Similar to the findings of Kellerman et al, ${ }^{61}$ youths believed they were not at risk of acquiring HIV infection and were influenced by the fear of getting a positive HIV-test result. Consequently, sexually active adolescents tended to shy away from HIV testing. Although racial/ethnic disparities in HIV testing have been reported in the USA, with AAs $(65 \%)$ and Hispanics (46\%) being more likely than whites
(41\%) to receive HIV testing, ${ }^{62}$ Bond et al ${ }^{16}$ summed up the barriers to getting tested for HIV as not feeling the need to get an HIV test coupled with the stigma associated with HIV. Therefore, to enhance HIV-testing rates among AA youths, more efforts are needed to reduce stigma, discrimination, and mistrust, considered a potential source of resentment toward HIV testing in the group. Since self-perception of risk may be important in health decision-making among AA youths, understanding the social mechanisms that lead to HIV testing might multiply opportunities to raise testing rates in this group. ${ }^{63}$ It is also necessary to raise awareness of getting an HIV test as a vital part of regular health checkups.

Several factors identified in the different levels of ecodevelopmental theory were associated with the epidemiological risk of contracting STDs/HIV after controlling for individuals' risk perception of infection. Microsystem variables - feel like talking to mother, have no trouble getting along with schoolteachers, perceive teachers treat students fairly, and have close friends who know how to use condoms correctly - were positively related to a low epidemiological risk of contracting STDs/HIV. Mothers' disapproval of adolescents' sexual debut in the exosystem was positively associated with low epidemiological risk of contracting STDs/HIV. However, being older, male, and mothers' positive attitude toward adolescents' use of birth control (in the exosystem) were associated with high epidemiological risk of contracting STDs/HIV. Ellen et $\mathrm{al}^{55}$ reported that young people's anxiety toward HIV appears to be related to the influence of peers and condom-use knowledge. Our study provides more information about the influence of social systems on adolescent risk of contracting STDs/HIV. Therefore, ecodevelopmental theory may serve as a valuable theoretical framework for guiding further STD/HIV studies and behavior-intervention programs. For example, it was not just the random peers, but rather the knowledge of "close friends", that impacted the adolescent's epidemiological risk of contracting STDs/HIV. Based on these findings, we strongly recommend that the epidemiological risk of contracting STDs/HIV can be reduced when importance is placed on enhancing mother-adolescent bonds and school bonds of students (especially the bonding between student and teacher) and knowledge of and access to condom use for all students.

This study revealed pivotal factors associated with the accuracy of risk assessment, eg, the dynamics of the adolescent-mother relationship and age. It was found that a worse connection with the mother (did not feel like talking to mother) and getting older were related to low accuracy of risk perception among AA youths. Only better communication 
with the mother and younger adolescents were significantly associated with youths' accurate assessment of the risk of STD/HIV infection. The study also showed a positive correlation between effective mother-youth communication and accurate assessment of the risk of STD/HIV infection. This implies that the imbalanced structure of AA families tends to weaken the connection with fathers, resulting in increasing significance of the mother. While dynamics between the mother and the youth are essential, these can be modified by various factors, such as mothers' interaction with other coparent(s) or biological father. ${ }^{38}$ It has been observed that seven in ten AA youths live with and are raised by a single mother. $^{50,51}$ Therefore, a stable family atmosphere and good communications between mother and child may determine the youth's ability to assess the risk of contracting STDs/ HIV accurately. After adjustment for self-risk perception, mothers' positive attitudes toward adolescents' birth-control use was found to be related to low accuracy of self-perceived risk. This is understandable, since a mother's positive attitude toward the adolescent's birth-control use can encourage the youth to adopt birth-control measures to avoid unintended pregnancies. It also indicates the need to emphasize the potential risk of STDs and the benefits of condom use (STD/ HIV and pregnancy prevention) during sexual intercourse to both the youth and their mother to improve the youth's risk assessment.

\section{Limitations and strengths}

Although this study may be considered innovative, it has some inherent limitations. First, even though the Add Health database includes many social contexts and domains, a selfreported cross-sectional survey may be subject to some bias, due to underreporting or social desirability. Second, this study examined only one wave of Add Health data, and thus a causal relationship cannot be established. Finally, we did not apply equal weights to the various risky sexual behavior factors used in the development of the epidemiological index, even though each factor has a different risk level. It is recommended that future studies take into consideration this important measure for enhancing the accuracy and application of the indices.

Despite these limitations, our study has some major strengths. This is the first study to apply a composite index of risks (epidemiological vs self-perceived risk) related to STDs/HIV, sexual behavior, and family function in young AA. This measurement is innovative, because it provides an opportunity to examine differences between youths' perceptions and actual behavioral risk when objective measures are not accessible. The instrument is also a composite of several independent variables which has the advantage of being more robust than uni-dimensional variables. In addition, this study examined associations among social contexts, actual and perceived HIV risk, and accuracy of measurements using ecodevelopmental theory, which allowed for better understanding of adolescents' unrealistic biases. Our study found a stronger connection between schoolteachers and the youths. Similarly, knowledge about condom use acquired from close friends was associated with low epidemiological risk of contracting STDs/HIV. Since Add Health is a longitudinal survey, the scientific goals of the survey continue to expand and evolve as participants age into adulthood. It will be interesting to explore the impact of adolescents' experiences and changes in behavior on adolescents' risk-taking, risk preference, and risky decisions during the transition to adulthood.

\section{Conclusion}

Through examinations of self-perceived and epidemiological indices and the independent factors, we found low and inconsistent congruence between self-perceived and epidemiological risks among AA youths, which tends to negate our study assumptions. Self-perceived risk was not a true reflection of level of exposure to epidemiological risk in this subpopulation. The high influence of ecological factors on risk estimates points to the need for targeted education at family, school, and community levels, and indicates that ecodevelopmentally based interventions may be valuable in preventing the risk of HIV transmission among AA adolescents. Our study identified two important AA cultural factors: imbalanced family function (caused by father's absence) and mother's negative attitude toward the use of birth control, which predispose young AAs to higher risk of contracting STDs/HIV. The study also noted that better dynamics between a youth and the mother were related to a lower epidemiological risk of contracting STDs/ HIV and higher accuracy in risk assessment. Even though much remains to be understood about the factors that affect AA youths at high risk of acquiring or transmitting STDs/ HIV, our analysis of the determinants of risk offers insight into how self-perceived risk among AA youths may be modified or aligned with epidemiological risk of acquiring STDs/HIV and used to make informed decisions in adopting behavioral change. To accomplish this task, some time may be required to change the relevant social attitudes and norms associated with the risk measurements. Also, research is needed to model the influence of familial and community environments on adolescents' health-compromising behaviors, including psychosocial capacities that restrain adolescents' ability to resist peer pressure. 


\section{Acknowledgment}

This research did not receive any grants or funding from any public, commercial, or not-for-profit agency.

\section{Disclosure}

The authors report no conflicts of interest in this work.

\section{References}

1. CDC. Centers for Disease Control and Prevention. Diagnoses of HIV infection in the United States and dependent areas, 2014. Vol 26. HIV Surveillance report 2015. Available from: https://www.cdc.gov/hiv/pdf/ library/reports/surveillance/cdc-hiv-surveillance-report-2014-vol-26. pdf. Accessed April 20, 2018.

2. CDC. Centers for Disease Control and Prevention. Updated Slide Set: HIV Surveillance - Epidemiology of HIV Infection: Epidemiology of HIV Infection through 2012. Available from: http://www.cdc.gov/hiv/ pdf/statistics_surveillance_epi-hiv-infection.pdf. Accessed July 17 2018.

3. CDC. Centers for Disease Control and Prevention. Youth risk behavior surveillance-United States, 2013. MMWR. 2014;61(4):SS6306.

4. CDC. Centers for Disease Control and Prevention. Youth risk behavior Surveillance-United States, 2015. MMWR. 2016;65:1-174.

5. D'Augelli AR, Hershberger SL. Lesbian, gay, and bisexual youth in community settings: personal challenges and mental health problems. Am J Community Psychol. 1993;21(4):421-448.

6. Fields EL, Bogart LM, Galvan FH, Wagner GJ, Klein DJ, Schuster MA. Association of discrimination-related trauma with sexual risk among HIV-positive African American men who have sex with men. Am J Public Health. 2013;103(5):875-880.

7. VanDevanter N, Duncan A, Burrell-Piggott T, et al. The influence of substance use, social sexual environment, psychosocial factors, and partner characteristics on high-risk sexual behavior among young black and Latino men who have sex with men living with HIV: a qualitative study. AIDS Patient Care STDS. 2011;25(2):113-121.

8. Arens CR, White TL, Massengill N. Attitudinal factors protective against youth smoking: an integrative review. J Nurs Scholarsh. 2014;46(3):167-175

9. Janz NK, Becker MH. The health belief model: a decade later. Health Educ Q. 1984;11(1):1-47.

10. Corte CM, Sommers MS. Alcohol and risky behaviors. Annu Rev Nurs Res. 2005;23:327-360.

11. Buzi RS, Smith PB, Weinman ML, Novello G. HIV risk perceptions among adolescents attending family planning clinics: an integrated perspective. AIDS Care. 2013;25(1):20-27.

12. CDC. Centers for Disease Control and Prevention. Bringing High-Quality HIV and STD Prevention to Youth in Schools: CDC's Division of Adolescent and School Health; 2014. Available from: http://www.cdc.gov/ healthyyouth/about/pdf/hivstd_prevention.pdf. Accessed July 05, 2017.

13. Jenner E, Jenner LW, Walsh S, Demby H, Gregory A, Davis E. Impact of an intervention designed to reduce sexual health risk behaviors of African American adolescents: results of a randomized controlled trial. Am J Public Health. 2016;106(S1):S78-S84.

14. Andersson-Ellström A, Forssman L, Milsom I. The relationship between knowledge about sexually transmitted diseases and actual sexual behaviour in a group of teenage girls. Genitourin Med. 1996;72(1):32-36.

15. Samkange-Zeeb FN, Spallek L, Zeeb H. Awareness and knowledge of sexually transmitted diseases (STDs) among school-going adolescents in Europe: a systematic review of published literature. BMC Public Health. 2011;11:727.

16. Bond KT, Frye V, Taylor R, et al. Knowing is not enough: a qualitative report on HIV testing among heterosexual African-American men. AIDS Care. 2015;27(2):182-188.

17. Arnett JJ. Optimistic bias in adolescent and adult smokers and nonsmokers. Addict Behav. 2000;25(4):625-632.
18. Weinstein ND. Unrealistic optimism about susceptibility to health problems: conclusions from a community-wide sample. J Behav Med. 1987;10(5):481-500.

19. Patton GC, Tollit MM, Romaniuk H, Spence SH, Sheffield J, Sawyer MG. A prospective study of the effects of optimism on adolescent health risks. Pediatrics. 2011;127(2):308-316.

20. Dillard AJ, Midboe AM, Klein WM. The dark side of optimism: unrealistic optimism about problems with alcohol predicts subsequent negative event experiences. Pers Soc Psychol Bull. 2009;35(11):1540-1550.

21. Perrino T, González-Soldevilla A, Pantin H, Szapocznik J. The role of families in adolescent HIV prevention: a review. Clin Child Fam Psychol Rev. 2000;3(2):81-96.

22. Prado G, Huang S, Maldonado-Molina M, et al. An empirical test of ecodevelopmental theory in predicting HIV risk behaviors among Hispanic youth. Health Educ Behav. 2010;37(1):97-114.

23. Szapocznik J, Coatsworth JD. An ecodevelopmental framework for organizing the influences on drug abuse: a developmental model of risk and protection. Drug abuse: Origins \& interventions. Washington, DC: US: American Psychological Association; 1999:331-366.

24. Bronfenbrenner U. The Ecology of Human Development: Experiments by Nature and Design. Cambridge, MA: Harvard University Press; 1979.

25. Wallace SA, Miller KS, Forehand R. Perceived peer norms and sexual intentions among African American preadolescents. AIDS Educ Prev. 2008;20(4):360-369.

26. Rostosky SS, Wilcox BL, Wright MLC, Randall BA. The impact of religiosity on adolescent sexual behavior: a review of the evidence. $J$ Adolesc Res. 2004;19(6):677-697.

27. Cubbin C, Santelli J, Brindis CD, Braveman P. Neighborhood context and sexual behaviors among adolescents: findings from the national longitudinal study of adolescent health. Perspect Sex Reprod Health. 2005;37(3):125-134.

28. Landor A, Simons LG, Simons RL, Brody GH, Gibbons FX. The role of religiosity in the relationship between parents, peers, and adolescent risky sexual behavior. J Youth Adolesc. 2011;40(3):296-309.

29. Whitaker DJ, Miller KS, May DC, Levin ML. Teenage partners' communication about sexual risk and condom use: the importance of parent-teenager discussions. Fam Plann Perspect. 1999;31(3):117-121.

30. DiClemente RJ, Wingood GM, Crosby R, Cobb BK, Harrington $\mathrm{K}$, Davies SL. Parent-adolescent communication and sexual risk behaviors among African American adolescent females. $J$ Pediatr. 2001;139(3):407-412.

31. Commendador KA. Parental influences on adolescent decision making and contraceptive use. Pediatr Nurs. 2010;36(3):147-156.

32. Malcolm S, Huang S, Cordova D, et al. Predicting condom use attitudes, norms, and control beliefs in Hispanic problem behavior youth: the effects of family functioning and parent-adolescent communication about sex on condom use. Health Educ Behav. 2013;40(4):384-391.

33. Whitbeck LB, Simons RL, Conger RD. The effects of early family relationships on contemporary relationships and assistance patterns between adult children and their parents. $J$ Gerontol. 1991;46(6):S330-S337.

34. Whitbeck L, Hoyt DR, Huck SM. Early family relationships, intergenerational solidarity, and support provided to parents by their adult children. J Gerontol. 1994;49(2):S85-S94.

35. Brown BB, Mounts N, Lamborn SD, Steinberg L. Parenting practices and peer group affiliation in adolescence. Child Dev. 1993;64(2):467-482.

36. Sieverding JA, Adler N, Witt S, Ellen J. The influence of parental monitoring on adolescent sexual initiation. Arch Pediatr Adolesc Med. 2005;159(8):724-729.

37. Bean RA, Barber BK, Crane DR. Parental support, behavioral control, and psychological control among African American youth: the relationships to academic grades, delinquency, and depression. J Fam Issues. 2006;27:1335-1355.

38. Parent J, Jones DJ, Forehand R, Cuellar J, Shoulberg EK. The role of coparents in African American single-mother families: the indirect effect of coparent identity on youth psychosocial adjustment. J Fam Psychol. 2013;27(2):252-262. 
39. Farrelly C, Cordova D, Huang S, Estrada Y, Prado G. The role of acculturation and family functioning in predicting HIV risk behaviors among Hispanic delinquent youth. J Immigr Minor Health. 2013;15(3): 476-483.

40. Coatsworth JD, Pantin H, Szapocznik J. Familias Unidas: a familycentered ecodevelopmental intervention to reduce risk for problem behavior among Hispanic adolescents. Clin Child Fam Psychol Rev. 2002;5(2):113-132.

41. Youniss J, Smollar J. Adolescent relations with mothers, fathers, and friends. Chicago, IL: University of Chicago press. 1987.

42. Allen JP, Hauser ST, Bell KL, O’Connor TG. Longitudinal assessment of autonomy and relatedness in adolescent-family interactions as predictors of adolescent ego development and self-esteem. Child Dev. 1994;65(1):179-194.

43. Kremen AM, Block J. The roots of ego-control in young adulthood: links with parenting in early childhood. J Pers Soc Psychol. 1998;75(4):1062-1075.

44. Morris M, Handcock MS, Miller WC, et al. Prevalence of HIV infection among young adults in the United States: results from the add health study. Am J Public Health. 2006;96(6):1091-1097.

45. National Longitudinal Study of Adolescent Health (Add Health), 19942008. Inter-university Consortium for political and social research 2014. Available from: http://doi.org/10.3886/ICPSR21600.v15. Accessed March 18, 2017.

46. Mgbere O, Monjok E, Abughosh S, Ekong E, Holstad MM, Essien EJ. Modeling covariates of self-perceived and epidemiologic notions of risk for acquiring STIs/HIV among military personnel: a comparative analysis. AIDS Behav. 2013;17(3):1159-1175.

47. LiYH, Mgbere O, Abughosh S, Chen H, Cuccaro P, Essien EJ. Modeling ecodevelopmental context of sexually transmitted disease/HIV risk and protective behaviors among African-American adolescents. HIV AIDS (Auckl). 2017;9:119-135.

48. Nathanson M, Baird A, Jemail J. Family functioning and the adolescent mother: a systems approach. Adolescence. 1986;21(84): 827-841.

49. Oman RF, Vesely SF, Aspy CB. Youth assets and sexual risk behavior: the importance of assets for youth residing in one-parent households. Perspect Sex Reprod Health. 2005;37(1):25-31.

50. Annie E. Casey Foundation. kids count data center 2011. Available from: https://datacenter.kidscount.org/. Accessed June 27, 2017.
51. United States Census Bureau. Current population survey, 2009 America's families and living arrangements 2009. Available from: https:// www.census.gov/prod/2011pubs/p70-126.pdf. Accessed July 10, 2016.

52. Harris AL. "I got caught up in the game": generational influences on contraceptive decision making in African-American women. JAm Assoc Nurse Pract. 2013;25(3):156-165.

53. Castro FG, Marsiglia FF, Kulis S, Kellison JG. Lifetime segmented assimilation trajectories and health outcomes in Latino and other community residents. Am J Public Health. 2010;100(4):669-676.

54. Simpkins SD, Delgado MY, Price CD, Quach A, Starbuck E. Socioeconomic status, ethnicity, culture, and immigration: examining the potential mechanisms underlying Mexican-origin adolescents' organized activity participation. Dev Psychol. 2013;49(4):706-721.

55. Ellen JM, Boyer CB, Tschann JM, Shafer MA. Adolescents' perceived risk for STDs and HIV infection. JAdolesc Health. 1996;18(3):177-181.

56. Whaley AL. Differential risk perceptions for unintended pregnancy, STDs, and HIV/AIDS among urban adolescents: some preliminary findings. J Genet Psychol. 2000;161(4):435-452.

57. Hoorens V, Harris P. Distortions in reports of health behaviors: the time span effect and illusory supefuority. Psychol Health. 1998;13(3):451-466.

58. Baker F, Dye JT, Denniston MM, Ainsworth SR. Risk perception and cigar smoking behavior. Am J Health Behav. 2001;25(2):10:106-114.

59. Eldridge GD, St Lawrence JS, Little CE, Shelby MC, Brasfield TL. Barriers to condom use and barrier method preferences among lowincome African-American women. Women Health. 1995;23(1):73-89.

60. Lapinski MK, Rimal RN, Klein KA, Shulman HC. Risk perceptions of people living with HIV/AIDS: how similarity affects optimistic bias. $J$ Health Psychol. 2009;14(2):251-257.

61. Kellerman SE, Lehman JS, Lansky A, et al. HIV testing within at-risk populations in the United States and the reasons for seeking or avoiding HIV testing. J Acquir Immune Defic Syndr. 2002;31(2):202-210.

62. CDC. Centers for Disease Control and Prevention. HIV testing in the United States. National Center for HIV/AIDS, Viral Hepatitis, STD, and TB Prevention, August 2016. Available from: https://www.cdc.gov/nchhstp/ newsroom/docs/factsheets/hiv-testing-us-508.pdf. Accessed November 23, 2018.

63. Lo CC, Runnels RC, Cheng TC. Racial/ethnic differences in HIV testing: an application of the health services utilization model. SAGE Open Med. 2018;6:1-8.
HIV/AIDS - Research and Palliative Care

\section{Publish your work in this journal}

HIV/AIDS - Research and Palliative Care is an international, peerreviewed open access journal focusing on advances in research in HIV, its clinical progression and management options including antiviral treatment, palliative care and public healthcare policies to control viral spread. The journal is included in PubMed. The manuscript man-

\section{Dovepress}

agement system is completely online and includes a very quick and fair peer-review system, which is all easy to use. Visit http://www.dovepress. com/testimonials.php to read real quotes from published authors. 